\title{
La historia clínica y la anamnesis en la psicopatología ac- tual. De la biografía a la biología. De la escucha y mirada clínica a la escucha y mirada por los aparatos. ¿Qué es la evidencia en salud mental?.
}

\author{
Medical history and anamnesis in current psychopathology. From biography to biology, from \\ clinical listening and look to listening and look through devices. What is evidence in mental health?
}

\author{
Federico Menéndez Osorio ${ }^{a}$. \\ ${ }^{a}$ Psiquiatra. \\ Correspondencia: Federico Menéndez,Osorio(femeos@telefonica.net)
}

Recibido: 11/07/2011; aceptado: 19/11/2011

RESUMEN: Los avances científico-técnicos han supuesto un cambio importante en los paradigmas clínicos, pasando de la mirada y escucha clínica a la mirada y escucha "escópica" o de los aparatos, (biopsia, escáner, anatomía patológica, laboratorio, radiología, etc.), que dictan la objetividad, la certeza y la mensurabilidad.

Este deslizamiento en base a la "evidencia" científica -lo matematizable y estadístico- cae, en ocasiones, en el cientificismo, al presuponer que la ciencia es la única forma de conocimiento válido y riguroso, sin tener en cuenta que no hay una ciencia de los valores, de lo humano, de la belleza, etc.

En Psicopatología, esta deriva del saber hacia las pruebas y la fetichización de lo científico, se intenta mimetizar, como parodia, por las escalas, cuestionarios, guías, pruebas, etc., en un afán de objetivar y mensurar lo que en otra dimensión es subjetivo y singular, despreciando en consecuencia el rigor, la sutileza, la creatividad, la fina observación y la descripción de las conductas y de lo psicopatológico, de la clínica clásica. El saber psicopatológico se nutre, entre otros, de los dos polos señalados, del saber científico y del saber clínico, sin que el segundo quede reducido o englobado en el primero. Es preciso determinar el estatuto, métodos y campo de conocimientos de cada unos de estos saberes, su complementariedad, su especificidad y su diferencia.

Es importante rescatar la importancia del relato, la historia, la patografía, la mirada y escucha clínica, así como lo subjetivo, singular y específico, como campo del saber propio de lo psíquico.

En definitiva mostrar la importancia de retomar en Psicoptalogía, las historias, el relato, la anamnesis, la biografía, la clínica del caso por caso; séase, construir una $\mathrm{H}^{\mathrm{a}}$ Clínica.

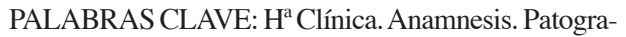
fía. Mirada y escucha clínica. Saber psicopatológico.
ABSTRACT: Scientific and technical improvements have meant an important change in clinical paradigms, moving from clinical look and listening to the "scopic" look and listening through devices (biopsy, scanner, pathological anatomy, laboratory, radiology, etc.), determining objectivity, certainty and mensurability.

This sliding, supported by the scientific "evidence" -liable to mathematics and statistics- sometimes becomes "scientificism" when supposed that science is the only way to knowledge, not considering that there is not a science of values, of the human, of life, of beauty, etc.

Psychopathology moves from knowledge to evidence turning the scientific into a fetish, and it tries to imitate, as a parody, through scales, questionnaires, guides, tests, etc., aiming at putting into objective terms and measuring the subjective and the singular, rejecting the rigor, the subtleness, the creativity, the fine observation and description of behaviors and the psychopathological following the classical clinics.

The psychopathological knowledge feeds on the clinical and scientific, knowledge, among others. We need to determine the statute, methods and field of each one of these konwledges, their complementarity, specificity and differences.

To recover the importance of the story, the history, the pathobiography, the clinical look and listening, as well as the subjective, singular and specific, as a field of knowledge belonging to the psychic.

To show, eventually, the importance of taking up again the psychopathology, the history, the story, the anamnesis, the biography, the case-to-case clinics; that is, to write a medical history.

KEY WORDS: Medical history, Anamnesis, Pathobiography, Clinical look and listening, Psychopathological knowledge. 
ORIGINALES Y REVISIONES

Introdución: la $H^{a}$ Clínica en la clínica.

La $\mathrm{H}^{\mathrm{a}}$ Clínica es el documento e instrumento mediante el cual a través de los tiempos se ha trascrito, recogido y reflejado -en cada época de una forma y con unas técnicas diversas- lo que es el proceso biológico de la enfermedad, las patografías, en definitiva la clínica. Es a través de la $\mathrm{H}^{\mathrm{a}}$ Clínica como podemos concebir y conocer el desarrollo de la clínica.

En el extenso, detallado y riguroso libro de Lain Entralgo acerca de la $\mathrm{H}^{\mathrm{a}}$ Clínica (1), nos muestra el desarrollo del conocimiento médico de las patologías y la práctica clínica, basándose en los relatos patográficos que recorren los diversos periodos históricos, que van, desde el pensamiento hipocrático hasta comienzos del siglo XX. Nos hace Lain un recorrido a lo largo de los siglos por el quehacer médico expresado y recogido en las $\mathrm{H}^{\mathrm{a}}$ Clínicas de cada época.

Medicina hipocrática.

Nace la $H^{a}$ Clínica con la Medicina hipocrática como un saber técnico, alejado de lo mágico o la divinidad, basándose en principios objetivos. Dominado por un afán de un saber trasmisible que al decir de García Gual (2) "no solo trataba de curar sino de ilustrar a sus pacientes" (p. 15) entendiéndose la enfermedad "como un proceso morboso que afecta al organismo en su conjunto" (p. 50) y "el sujeto de esa $H^{a}$ no es la enfermedad, sino el paciente con su naturaleza individual y su organismo humano" (p. 54).

Para Lain (1), estas primeras Historias clínicas muestran ya la función docente del relato, que nos enseña a "Saber ver" y "Saber hacer"; destacando la precisa fidelidad a la realidad clínica y la exquisita individualidad de la narración patológica. "El enfermo es contemplado y descrito como un ente estrictamente singular y original"... (p. 731).

Renacimiento e Ilustración.

Va a ser con la entrada en la Modernidad y más concretamente con el Renacimiento, cuando se hará hincapié en la individualidad de la $H^{a}$ Clínica "poniendo a la enfermedad en el marco de la biografía del enfermo"... (p. 733).

Para Sydenham, formulador de la nosología moderna, las historias clínicas se atenderán a los datos de la experiencia con el enfermo y sus patografías van a ser empíricas y rigurosamente específicas (p. 733). Describió ya por entonces "la Histeria en los hombres, aunque mas raramente que en las mujeres" (p. 167).

Siglo XIX.

A finales del Siglo XIX en los textos de las historias clínicas aparece la "descriptio subjecti" (p. 735), la importancia dada al individuo humano. Hasta entonces en el relato patográfico el individuo aparecía troceado y dividido en mil pedazos; era la $\mathrm{H}^{\mathrm{a}}$ Clínica de un hígado, pulmones, sangre, etc. El sujeto quedaba reducido a mero organismo. 
ORIGINALES Y REVISIONES

Comienza en esta época -finales del siglo XIX- a darse mayor importancia al relato biográfico de la vida como historia. "Para que una patografía sea auténtica deberá ser personal; para ser científica, en alguna medida, universal"... (p. 740).

Desde el vitalismo pasando por los neuropatólogos como Jackson, Von Monakow, Goldstein y posteriormente Von Weizsäcker, la escuela de Heidelberg o Freud, el relato patográfico se abre, como refiere Tiburcio Angosto, a la individuación, en tanto el cuadro clínico es visto como "una creación adaptativa del organismo". Asimismo se tiene en cuenta "la vida personal y la mentalidad antropológica tomándose la enfermedad individual como un momento constitutivo de la total biografía del sujeto" (3).

Se plantea el estatus de las enfermedades psicosomáticas y las enfermedades funcionales en el sentido que Freud señalaba al respecto de las teorías de la histeria de Charcot, de que las parálisis histéricas se comportaban como si la anatomía no existiese, es decir, según la concepción vulgar, popular, de los órganos y del cuerpo en general.

Con Freud la $\mathrm{H}^{\mathrm{a}}$ Clínica es patoautobiográfica en tanto el paciente narra no solo sus síntomas, sino también su vida o lo que se cree que es su vida (p. 7-8). Freud va a des- velar el campo del inconsciente.

Se recogen, siguiendo el ya citado libro de Lain (1), algunos textos de autores neuropatólogos que muestran muy claramente la evolución de la $\mathrm{H}^{\mathrm{a}}$ Clínica, el relato y la anamnesis, así como la visión de las patologías y de la enfermedad en esa época.

Mientras que Broca y los localicionistas valoraban en la lesión lo que el enfermo presentaba como alteración o déficit, atribuyéndolo a dicha lesión anatómica circunscrita. Jackson en cambio, creía que la lesión anatómica no era la causa de las aboliciones o irritaciones locales como diría Broca, sino que las alteraciones presentadas, eran consecuencia de la respuesta de todo el sistema nervioso, que actúa fisiológica y morfológicamente como un todo (p. 496).

\section{El proceso biológico llamado enfermedad.}

Para Von Monakow (p. 532) las notas definitorias del proceso biológico que llamamos enfermedad se caracteriza:

$1^{\mathrm{o}}$ Por ser una respuesta biológica adaptativa y creadora.

$2^{\circ}$ Es una respuesta proferida por el totum del organismo enfermo.

$3^{\circ} \mathrm{La}$ radicalidad individual de cada respuesta. Lo que le llevaría a repetir y reafirmar "no hay enfermedades, sino enfermos". 
Pero va a ser Goldstein, desde su experiencia neurológica quien hará hincapié en la importancia del relato patográfico y en los aspectos psicológicos en la Historia Clínica, reiterando que en la configuración de un síntoma colabora el organismo entero, así como que todo el organismo es por definición individualmente distinto de los restantes, de tal modo que la determinación de la enfermedad exige como punto de partida el concepto esencial de individuo

La reflexión sobre la obra de Goldstein lleva a Laín a señalar que si el punto de vista adoptado hubiese sido "antropobiológico" y no meramente "biológico", no habría dejado de añadir en sus teorías que: "la última diferencia de cada síntoma, se halla determinado por la condición personal del paciente, por ser este "persona" y "tal persona"..."la libertad y la biografía del enfermo -y no solo su organismo en el sentido estrictamente biológico- interviene en todas sus respuestas tanto sanas como morbosas"... "Junto a los síntomas biológicos, hay otros derivados de su condición de persona, de mucho valor para la plena comprensión del cuadro clínico"... (p. 541). "En cada síntoma hay que ver la respuesta de todo el organismo. El sistema nervioso es un aparato unitario que siempre trabaja como un todo" (p. 542).

Pero donde la $H^{a}$ Clínica alcanza su valor en lo subjetivo y personalizado, con una visión antropológica, es con Von Weizsäcker, creador de la "nueva neurología" para quien "la enfermedad de un hombre tiene algo que ver con su verdad, esto es, con la verdad" (p.631)... "La estrecha relación entre la enfermedad de un hombre y la verdad de su ser... la meta del conocimiento médico, no es el diagnóstico de una enfermedad en el sentido habitual del término, sino entender la verdad de una vida humana" (p. 637).

Y sigue señalándonos Von Weizsäcker “... La $H^{a}$ clínica posee el valor y ocupa el lugar que las observaciones experimentales o sistemáticas tuvieron en las ciencias de la naturaleza. La $H^{a}$ clínica es el documento inicial, elemental y fundamental de todo saber médico" ( $p .644)$... "La plenitud de la biografía de un hombre y no solo su dimensión biológica, influye de algún modo en la configuración sintomática de sus dolencias"... (p. 647).

Ortega y Gasset precisaba con claridad la diferencia entre vida biográfica y biológica al señalar: "algunos pensarán que la vida es el proceso existencial de un alma y los otros que es una sucesión de reacciones químicas. El sentido primario y radical de la palabra vida aparece cuando se la emplea en el sentido de biografía y no en el de biología, por la fortísima razón de que toda biología es en definitiva solo un capítulo de ciertas biografías, en lo que en su vida-biografiable- hacen los biólogos. Otra cosa es abstracción, fantasía y mito”... (4). 
ORIGINALES Y REVISIONES

La clínica y la psicopatología actuales.

Después de este muy resumido recorrido a través de las $\mathrm{H}^{\mathrm{a}}$ Clínicas y las patografías en la obra de Lain, ¿con qué nos encontramos en la clínica actual?

$\mathrm{Si}$ hacemos un repaso de las $\mathrm{H}^{\mathrm{a}}$ Clínicas y la semiología en los tiempos actuales nos encontramos que en la clínica en general y en las especialidades en particular, los adelantos científicos-técnicos (pruebas complementarias, exámenes radiográficos, analíticos, etc.) han supuesto un corte radical con la visión tradicional y clásica del quehacer clínico, tanto en la observación como en la evolución diagnóstica.

Ya no son la semiología, la exploración, la anamnesis y la $\mathrm{H}^{\mathrm{a}}$ Clínica tradicional quienes marcan la pauta del diagnóstico. Éste viene determinado por la "objetividad" y mensurabilidad de las pruebas. Ya no es la mirada y escucha clínicas quienes definen y determinan el diagnóstico y la veracidad, sino la mirada "escópica", a través de lo que nos muestran los aparatos y técnicas exploratorias: endoscopias, escáneres, radiografías, biopsias, anatomía patológica, laboratorio, etc., etc. (el médico mira más al ordenador y a los aparatos que al paciente). ... "la clínica busca el amparo y aval científico en las ciencias duras, objetivables: la física y la matemática” (5), "la vertiente del tecnoculto" que diría P. Virilio.

Como afirma G. Canguilhem "El conocimiento actual de las enfermedades somáticas es la culminación de una sucesión de crisis e intervenciones del saber médico.... en el que se desplazaron los lugares de observación y análisis de las estructuras orgánicas sospechosas en función de aparatos y de técnicas propias o prestadas. Las enfermedades fueron así sucesivamente localizadas en el organismo: el órgano, el tejido, la célula, el gen, la enzima" (6).

"El médico terapeuta para todo servicio, llamado generalista, vio declinar su prestigio y autoridad en beneficio de los especialistas, ingenieros de un organismo desarmado como una maquinaria. Médicos todavía por la función, pero ahora no en concordancia con su imagen secular, cuando la consulta se hace por computadora a bancos de datos de carácter semiológico y etiológico y en la formulación de un diagnostico probabilístico, apoyado en la evaluación de informaciones estadísticas" ( $p$. 40).

"El triunfo del laboratorio sobre la clínica estableció una seguridad y cientificidad que antes estaba condicionada por la incertidumbre” (7) (además de defensa juridica con los protocolos, etc).

Esto es lo que J. Peteiro describe como "la ontologización de la enfermedad", en tanto atribución de ser a la enfermedad como algo separable del enfermo. Esta ontologización de la enfermedad está facilitada por una creciente especialización por órganos y aparatos anatómicos que suponen una peregrinación por intercon- 
sultas y exploraciones, con el olvido de su ser como enfermo y una anulación del sujeto que sufre" (8).

Este intento de alojarse bajo el templo de la ciencia y la creencia de que esto da absoluta certeza, veracidad y objetividad, no deja de ser una búsqueda de aval y defensa contra la incertidumbre, el temor y la angustia, ante el saber y el conocimiento.

La propia ciencia no puede dar cuenta de tales certidumbres y seguridades. Así la mecánica cuántica introduce la indeterminación como elemento inherente a la medición de cualquier estructura física y Gödel demostró que en todo sistema lógico coherente, hay afirmaciones cuya veracidad o falsedad no puede ni demostrarse, ni refutarse (5) (p. 76). Este es el límite del conocimiento científico que los propios científicos y la filosofía de la ciencia han demostrado.

¿Qué ha ocurrido mientras tanto en la clínica psicopatológica? Lo que vendría a representar dichos avances científico-técnicos de objetivación, equivalentes a las pruebas, aparatos y exámenes complementarios de las otras especialidades antes descritas, no los tenemos en psicopatología.

Aunque hemos experimentado un prodigioso avance en este campo y dispongamos de descubrimientos alentadores (escáner, imágenes cerebrales, cartografía cerebral, genética, neurotransmisores, etc.) que nos acercan a poder dar cuenta de las supuestas lesiones y etiologías y poder ser objetivables, buscando la equiparación y la acreditación científica de otras especialidades, en busca de la certeza y la cientificidad, estamos aún lejos de ellas.

Por el contrario, lo que supuso -y de lo que todavía hoy disponemos si se sabe aplicar- la fina y minuciosa observación y descripción de las conductas y los casos clínicos de la psiquiatría y psicología clásicas, ha perdido su interés y rigor, suplantadas por una serie de escalas, cuestionarios, ítems, pruebas complementarias, etc. Se intenta así mimetizar, falsamente, las pruebas de otras especialidades, no teniendo en cuenta lo específico de lo psíquico y lo mental, despreciando y confundiendo el objeto de estudio y el campo propio del conocimiento que nos acredite, dentro de la clínica, como nuestra especialidad (ver figura 1).

\section{Conocimiento-saber-ciencia. El cientificismo.}

Este deslumbramiento y fetichización -por no decir papanatismo- creer que lo único y pretendidamente científico es sinónimo de lo físico y matematizable- es decir, en el ámbito médico y psicopatológico, lo orgánico y lo biológico -siguiendo los parámetros de las ciencias físicas-, no dejaría de ser puro cientificismo en el sentido que el término tiene de de creer que la ciencia es la única posibilidad de conocimiento. 
ORIGINALES Y REVISIONES

Es lo que D. Innerarity señala, "en la sociedad del conocimiento aumenta la significación del saber pero disminuye la relevancia de la ciencia... una sociedad del conocimiento no es aquella en la que la ciencia tiene una gran importancia, sino aquella en la que el saber tiene una gran importancia... en la sociedad del conocimiento existen una gran variedad de tipos de saberes, en parte concurrentes... por eso las políticas del conocimiento han de establecerse como políticas de la diversidad del conocimiento" (9).

La ciencia es una forma de saber y de acceder al conocimiento ("sociedad del conocimiento"). Entre las variedades del "conocimiento", no solo está la ciencia físico-matemática, hay un saber de los valores, un saber de la vida, de lo humano o de la belleza, que no viene determinado por lo científico, sino por otros tipos de saber. La ciencia físico-matemática no da cuenta de verdades absolutas, no agota la riqueza de una realidad compleja, que no puede ser reducida por completo a sus presupuestos (ver figura 1).

Podríamos, más en concreto, referirnos asimismo, al rigor dudoso de algunos experimentos en lo que atañe al campo de la psicopatología y las enfermedades mentales partiendo de una de las más elementales interrogantes: ¿la experimentación animal, dice algo acerca del lenguaje, lo simbólico, el inconsciente, el delirio... de todo lo cual los animales carecen? ¿Puede delirar un ratón, o un animal?

Y con respecto a las precauciones metodológicas en toda experimentación biológica, siguiendo a Von Uexküll o a Canguilhem y otros biólogos y neurocientíficos, nos alertan acerca de que "...los fenómenos que nos encontramos en la vida de una determinada especie biológica no son transferibles a otras especies. Las experiencias y por tanto las realidades de los organismos diferentes son inconmensurables entre sî'... (10). (Todo lo cual, no quiere decir, que no sea válida y necesaria la experimentación, sino que hay que tomarla con rigor y cautela).

En este sentido, Erwing Wagner (pionero en el trabajo con ratones transgénicos, científico del centro de investigaciones oncológicas en el Instituto de Patología Molecular de Viena), afirma: “...en el estudio con ratones transgénicos y el paso a humanos es un paso muy grande. No podemos hacer personas transgénicas.... Investigamos con los ratones y con cultivos de células humanas e intentamos hacer correlaciones, pero no podemos estar seguros de que un gen vaya a funcionar en el ser humano"... (11).

Este deslumbramiento cientificista ha llevado a que perdamos el rigor y la riqueza de la sutileza y finura de la semiología clásica, de la observación y la anamnesis, de la escucha y la mirada clínica, de la creatividad, como modo de conocimiento -tachados ahora de métodos obsoletos y esquemas periclitados- para quedarnos reducidos a la mirada escópica de los aparatos y las pruebas, o a los cuestionarios, escalas, guías, test, etc, etc. 
Perdemos de esta manera, lo que ya teníamos como conocimiento y riqueza descriptiva y semiológica del estudio de los casos clínicos, para quedarnos con el humo de lo pretendidamente objetivable y mensurable, en tanto tecnoculto y cientificismo.

Este reduccionismo biologicista, mecanicista y falsamente científico de lo psíquico, supone confundir los métodos y conocimientos del estudio de las vísceras y de los órganos, con lo que suponen los fenómenos mentales como fenómenos emergentes de esos órganos, en tanto funciones propias y específicas. (véase esquema)

López Ibor, exponía acerca del enfermo psíquico, a diferencia del enfermo somático, en una de sus reflexiones sobre la psicosomática: "Un hombre tiene mas estratos, vertientes, líneas y curvas de los que supone poseer una colecistitis. La enfermedad está enclavada en su vida. No es un hecho biológico cualquiera; es un acontecimiento personal... el diagnóstico personal supone una valoración de la enfermedad como acontecimiento en la historia del enfermo"... (12).

El reducionismo biologicista y organicista.

El reduccionismo biologicista, hace que nos olvidemos de lo que está sobre la mesa, como centro y base del debate epistémico de nuestro campo clínico, con respecto de lo que entendemos, también y además, como nuestro objeto de estudio: la conducta, la enfermedad mental, lo simbólico, lo inconsciente, los afectos, etc.

Es partiendo de esta especificidad como cabe preguntarse y plantearse qué es lo objetivable y mensurable en psicopatología, cómo esto se nos presenta; qué métodos de conocimiento le son propios; qué técnicas e investigaciones le corresponden para su estudio; qué variables e interrelaciones están implicadas y cómo estas interactúan....

En la línea de lo anteriormente descrito, Berrios hace una acerada crítica a la Medicina Basada en al Evidencia (M.B.E) y su extrapolación y aplicación en la psiquiatría afirmando: "es una parodia epistemológica que se pida a los psiquiatras que acepten la M.B.E. sin mas evidencias que el chantaje moral creado por aquellos que afirman que las matemáticas son la forma mas elevada de ciencia y por lo tanto que lo que es matemáticamente demostrable supera todo lo demás"..."nunca se ha diseñado un ensayo a gran escala que demuestre que prescribir y tomar decisiones fundadas en la M.B.E. sea significativamente mejor que la toma de decisiones basadas en el conocimiento y en la experiencia de los médicos"... (S. Rose y otros neurocientíficos vienen a señalar conclusiones similares que luego citaré).

Y con respecto a las guías clínicas sigue señalando Berríos: “...Dichas guías en la práctica, destruirían la espontaneidad terapéutica de la psiquiatría y cambiaria el antiguo arte de prescribir, que pasaría de ser creativo y flexible a mecánico y uniformado" (13). 
ORIGINALES Y REVISIONES

Luria recoge de Vigotski: "para explicar las formas mas complejas de la vida consciente del hombre es imprescindible salir de los limites del organismo....hay que buscar los orígenes de la vida consciente y del comportamiento no en las profundidades del cerebro ni del alma”... "sino en la relación del hombre con la realidad en su historia social, estrechamente ligada con el trabajo y el lenguaje..." (14).

Al decir de Althusser "no existe continuidad de esencia entre la existencia biológica del hombre y su existencia histórica..." (15).

Desde otros campos, más concretamente neurocientíficos, nos alertan del reduccionismo científico y del nivel de conocimientos que se están difundiendo como verdades científicas absolutas y simplistas, que chocan con la cruda realidad de la complejidad de nuestro campo psíquico.

Por ejemplo, A. Damasio, al referirse a la relación entre los neurotrasmisores y otras sustancias, nos advierte: "reducir la depresión a una afirmación sobre la disponibilidad de serotonina o norepinefrina, en general, es inaceptablemente tosco. Se establece una relación entre las sustancias, los circuitos, los receptores, las neuronas y el sentimiento, pero no nos dice nada de cómo se pasa de unos a otros... comprender la neurobiología de los sentimiento requiere comprender estos últimos..." (16).

En la misma línea, S. Rose (biólogo molecular; neurocientífico; director del grupo de investigación del cerebro y la conducta de la Open University de Londres) señala al respecto: "el que se haya descubierto el modo de actuación y eficacia del alguno de los fármacos antidepresivos o ansiolíticos, que actúan a nivel de los neurotransmisores con los que interactúan, y deducir de ahí, que sean los déficits de los sistemas neurotransmisores las causas de los trastornos psiquiátricos por los que se recetan, es un paso pequeño y aparentemente lógico, pero no exacto (exjuvantibus)... es como si alguien tiene dolor de muelas y toma aspirina que le alivia el dolor, no debería llegar precipitadamente a la conclusión de que la causa del dolor sea que tiene poco acetilsalicílico en el cerebro.... La aspirina puede bloquear la sensación del dolor y la clorpromazina o las benzodiazepinas pueden mitigar la ansiedad, sin revelar nada sobre el agente causal"..."una correlación no es una causa..." (17).

“... los neurotransmisores y neuromoduladores conocidos, Dopamina, Serotonina, GABA, etc. se han propuesto en uno u otro momento como la causa de la esquizofrenia, una causa que se desvanece en cuanto se impone una nueva moda en la industria farmacéutica...” (p. 284).

Y más explícitamente P.M. Etxenique señala: "las propiedades de la vida como la conciencia, la belleza, o problemas neurológicos, pueden no tener sentido a escala celular. Es decir, puedes saber que ley física gobierna la vida, pero ¿eso quiere decir que entendemos la vida, la belleza de un cuadro, el amor, o el pánico en un estadio?..." (18). 
Los descubrimientos y debates más actuales sobre la neurogénesis, la plasticidad cerebral, el funcionamiento neuronal y sináptico, la cartografía cerebral, etc., suponen una ruptura con las ideas al uso localicionistas, mecánicas, fijas y simplistas que se nos están transmitiendo por ciertos divulgadores y revistas.

Así por ejemplo, en el sentido de esta revisión de conceptos y nuevos descubrimientos, el neurólogo e investigador español Álvaro Pascual-Leone (director del laboratorio de estimulación magnética cerebral y profesor de la Universidad de Medicina de Harvard) nos dice: “...el sistema nervioso es fundamentalmente plástico, está cambiando de forma dinámica, cualquier acto que lleva a cabo nuestro cerebro modifica el cerebro mismo..." (19).

En esta misma línea van las investigaciones del neurocientífico Mriganka Sur en el Instituto Tecnológico de Massachusset que "recableó" la mente de un hurón de manera que la información procedente de su retina quedara conectada a su corteza auditiva. Los hurones seguían viendo, es más, su corteza auditiva se parecía la corteza visual, incluyendo neuronas y mapas espaciales afinados para detectar rasgos de luz. Se generó una nueva cartografía cerebral (20).

Esto venía a demostrar que el vínculo entre áreas del cerebro y las experiencias concretas -percepción visual, auditiva, senso motriz, etc -son plásticas y maleables. Si queremos entender porque algunas células o regiones cerebrales participan en la vista y no en la audición o al revés, deberemos buscar más allá de la propia actividad neurológica (21).

Es lo que le hace decir a S. Rose (17), "el cerebro de hoy no será el de mañana y no es el de ayer" (p. 178). Y a J. Lehrer "al igual que el sistema inmunológico se modifica como respuesta a los patógenos que encuentra, el cerebro está adaptándose constantemente a las condiciones cambiantes de la vida" (22).

\section{El reducionismo genético.}

Algo similar ocurre con los descubrimientos en el campo de la genética actual. Frente al simplismo de presuponer que tal enfermedad es debida a tal gen, (salvo en las enfermedades monogénicas), nos encontramos que por el contrario en el funcionamiento genético hay complejos y variados mecanismos interactuantes.

Así, C. Venter (genetista, autoridad mundial en el campo de la genética) afirma, "la mayoría de los científicos que trabajan en este campo no creen en el determinismo genético, excepto en un número muy limitado de enfermedades poco corrientes y con fuerte componente genético. La biología en general no actúa de esta forma y desde luego, no lo hace en el campo de la inteligencia y del comportamiento"... “a muchas personas les gustaría eximirse de responsabilidad y echarle 
ORIGINALES Y REVISIONES

la culpa a su código genético (fumadores, drogadictos, por ejemplo). El código genético no va a absolver a los seres humanos de sus decisiones individuales, ni de su responsabilidad personal. Nadie podrá refugiarse detrás de sus genes." (23).

Como refiere J. Peteiro (8), el éxito alcanzado en enfermedades debidas a alteraciones de un solo gen, han facilitado un reduccionismo extremo, al suponer que toda enfermedad pueda tener un gen responsable. "Esto es lo que se intenta errónea y acientíficamente aplicar en la Psiquiatría” (p. 64). Nuevos hallazgos muestran la ingenuidad de perseguir un patrón mendeliano, monogénico, revelando por el contrario el carácter poligénico subyacente en la psicosis y su relativa debilidad determinista.

Asimismo, prosigue Peteiro, se echan por tierra las visiones simplistas genéticas y se abren nuevas vías complementariamente innovadoras, que rompen con los reduccionismos dominantes que intentan hacer de la genética un "oráculo científico" que no cuestione y que dé exactitud y sea determinista. Así tenemos los descubrimientos actuales de los intrones, los genes chatarra, las mutaciones aleatorias, la epigenética ... de tal forma que el propio concepto de gen ha cambiado drásticamente respecto a la idea inicial, en la que se le consideraba como una secuencia inalterada de sus bases nucleotídicas. Y concluye Peteiro "el gran problema deriva de reducir y contemplar al ser humano como la consecuencia de un manojo de genes" (p. 86-87) (Podríamos añadir: o de una lesión cerebral o de alteraciones de neurotransmisores, etc).

Pero bien, para no extenderse más en este debate sobre la etiopatogenía en Salud Mental y resumirlo, cito textualmente lo que viniendo de un biólogo molecular y neurocientífico, S. Rose (17), pueda sernos útil y aleccionador en nuestra práctica clínica y en el respeto a los límites del saber y el rigor en el pensar:

* “Creer que la bioquímica es de algún modo mas fiable que los sentimientos que comunica una persona, será un ejemplo de lógica ex-juvantibus"... "no hay, ni puede haber una relación directa entre la complejidad de nuestras experiencias mentales y la simplicidad de una sola medida bioquímica...” (p. 248).

* "La bioquímica y la biología molecular no son lugar donde buscar la sede del alma. Son necesarias estas ciencias que posibilitan los conocimientos de la actividad cerebral y mental. Pero no contienen, ni determinan nuestro pensamiento, ni nuestra habilidad o capacidad para obrar..." (p. 172).

*”...La tendencia actual entre algunos neurocientíficos sigue siendo decididamente reduccionista en su insistencia en las exploraciones moleculares. De la misma manera que la actividad mental y la conciencia no se pueden reducir a la bioquímica, tampoco se puede reducir a unas sinapsis o unas neuronas concretas..." (p. 178).

*”En el cerebro no hay ningún lugar donde la neurofisiología se convierte en psicología...” (p. 186). 
ORIGINALES Y REVISIONES

El valor del relato y la patografía. El lenguaje.

Dicho lo anterior, retomaremos la importancia de la Historia Clínica y de la anamnesis. El valor de la finura y sutileza de la observación a través de la mirada y la escucha clínica.

Con respecto a la anamnesis A. Szczeklik (5) describe con gran belleza y rigor: "En la Medicina la situación que se da, es el encuentro entre dos personas: enfermo y médico ... el enfermo acude con su dolor, con su aflicción, su sufrimiento, su temor y pide socorro .... Y el enfermo habla. Hay que escucharle, oír su historia ... y de vez en cuando es necesario hacerle una pregunta, aclarar un detalle, determinar una cronología, etc. Para el narrador (el paciente) es lo mas importante de su vida..." (p. 16).

Para Platón, la anamnesis es un acontecimiento previo que se anticipa a la percepción. Antes de que el médico empiece a "percibir" - antes de explorar, auscultar, percutir, antes de los exámenes previos- escucha una historia del pasado. Con una palabra oportuna, ayuda a que salga a la luz un conocimiento, que es reminiscencia de algo que ha sucedido (p. 17).

Para los griegos la anamnesis era el camino que conduce al mundo de las ideas. Era preciso recordar aquel tiempo para conocer la verdad y encontrar el sitio que le corresponde a cada uno en el Ser (p. 20). "Por eso la importancia de la anamnesis. Se debe sentir curiosidad por oír la historia para que el enfermo note, tal vez por primera vez en su vida, que alguien está realmente interesado por su sufrimiento..." (p. 17).

Haciendo referencia a la palabra en la medicina de la Grecia antigua, nos señala Lain (24): "Había una medicina sin palabras o "tiránica”, propia para el tratamiento de los esclavos y otra medicina verbal o "amistosa”, la que resulta de la conjunción técnica entre un médico libre y un hombre libre" (p. 20). "El sentido biográfico de una experiencia cualquiera no puede ser visto, como quien mira un cuerpo, en tanto que cosa, tiene que ser narrado" "Mirado como desorden objetivo del cuerpo, en tanto que cuerpo, la enfermedad se rebela en un silencio preverbal, considerada en cambio como alteración de una biografía, la afectación morbosa tiene que manifestarse precisamente en la palabra: morbus in verbo..." (p. 27).

Este valor de la palabra, del relato de lo que supone la anamnesis y la historia, la biografía del paciente, lo explicita en su texto E. Lledó (25) al decir... "los mortales dotados de palabra son capaces de levantarse sobre el nivel de la naturaleza, gracias a esa posibilidad de configurar sus propias vidas y poderlas decir... El quien eres, pregunta por lo que has hecho, lo vivido, lo gozado o sufrido, lo querido, lo logrado o perdido, lo olvidado... el quien eres abre la puerta del lenguaje para que, en ese infinito territorio, hablemos nuestras propias palabras y recobremos el presente..." (p. 44-45). 
ORIGINALES Y REVISIONES

Es tal el valor del relato, de la biografía, que hace afirmar a Lledó "las palabras que emitimos, el lenguaje que hablamos constituye en realidad lo que somos" (p. 55)... "No cabe pues conocimiento de la individualidad sin la especulación de las palabras..." (p. 66) una mente sin palabras es una mente ciega, una inteligencia paralizada e inerte" ( $p .90)$. Como afirma Heidegger: "el lenguaje es la casa del ser... en su morada habita el hombre" (26).

Abundando en esta idea de la importancia del lenguaje y acerca de la acción en el cerebro de la palabra y la psicoterapia, E. Kandel, afirma: "en la medida en que nuestras palabras producen cambios en la mente de nuestros pacientes, las intervenciones psicoterapéuticas producen cambios en su cerebro". Estudios cerebrales realizados recientemente en pacientes antes y después de someterse a psicoterapia o psicoanálisis demuestran que el cerebro se reorganiza plásticamente tras el tratamiento y concluyen que ya no puede existir duda de que la psicoterapia puede propiciar cambios detectables en el cerebro (27).

Muchos siglos antes, el sofista grieto Protágoras se refería a la curación por la palabra cuando comparaba al retórico con el médico, pero con un médico que cura con palabras y no con píldoras. El filósofo (Protágoras) encuentra a una persona que en su opinión necesitaba ser orientado. Se acerca a ella y le habla. Si lleva a cabo su labor con eficacia, sus palabras actuarán como si de una medicina se tratara y cambiarían tanto las ideas como la actitud general de la persona que parecía tan descaminada. Si se hacen las cosas bien, tanto él como su paciente percibirán que la medicina ha surtido efecto.

Cuando la técnica de la palabra es eficaz y correcta, entonces dará resultado, al igual que con la píldora que si no es eficaz ni adecuada no lo dará y de todo ello serán los hechos y sus resultados quienes nos lo confirmarán (28).

Laín (29) nos señala que Platón, a su vez, elaboró toda una doctrina acerca de la acción psíquica y somática de la palabra, "la palabra (como las píldoras), es Pharmakon - medicamento o veneno - según las intenciones con que se emplee, puesto que esa palabra modifica la phisis de quien la oye" (p. 106). La palabra oportuna del médico puede ser iatros logos y no solo porque a veces cura o alivia, sino también porque enseña y consuela (p. 81).

Para Aristóteles la palabra tiene un triple poder: cuando es razonamiento dialéctico, convence; cuando es discurso retórico, persuade; y cuando es poema trágico, purga y purifica (p. 261). Podríamos decir que toda la tragedia griega es catártica.

Destaca Castilla del Pino que hay dos disciplinas, la Sociología y la Lingüística que han sido ignoradas por la psiquiatría desde el comienzo del siglo XX, y si grave es darle la espalda a las ciencias que puedan enriquecerla, mas es en el caso de la lingüística, si se piensa que los síntomas de los cuadros psiquiátricos los detectamos porque se no hablan, resulta incomprensible que se pudiera hacer psicopatología ignorando la obra de Saussure o Karl Buhler. Algunas de las desafor- 
ORIGINALES Y REVISIONES

tunadas postulaciones de Schneider acerca de la estructura de las ideas delirantes se hubieran evitado si hubiera conocido la obra de Saussure y me refiero solo a su distinción entre significado y significante (30).

Paradójicamente llama la atención, que otros saberes, como la Economía, recoge por la puerta lo que en nuestro campo arrojamos por la ventana. Así, Premios Nobel de Economía, como Stiglitz; Amartthya Sen o Akerlof dan un valor importante en sus análisis económicos a los subjetivo, lo irracional, los sentimientos, lo inconsciente, las vivencias... a las historias.

Concretamente Akerlof (Premio Nobel de Economía 2001), en su libro Animal Spirits afirma: "En las grandes decisiones de la economía y las finanzas los análisis macro y microeconómicos no son solo los mas importante e influyentes factores a tener en cuenta, sino que los factores psicológicos y emocionales en forma de intuición, miedo, desconfianza, fe, etc. están detrás de los comportamientos financieros, económicos e inversores" ... y prosigue ..." gran parte de las motivaciones de las personas proceden de la historia de sus propias vidas, una historia que se cuentan ellos mismo y que constituyen un encuadre para sus motivaciones. Las historias y la narración de sucesos son un elemento fundamental para el conocimiento humano"......"la conversación humana tiende a tomar la forma de una narración reciproca de historias... nuestro sentido de la realidad, quienes somos y lo que hacemos se entremezclan con la historia de nuestra vida y con la de los demás. El conglomerado de estas historias constituye una historia parcial y universal que por si misma representa un papel importante en la economía..." (31).

Esto es solo una muestra del valor de la palabra y la historia clínica y como despreciado por algunos en nuestro quehacer, es asimilado e integrado por otras ciencias o saberes, como referentes para su conocimiento y aplicación. La subjetividad, lo propio y específico de lo humano, en tanto su singularidad - de la cual el lenguaje da cuenta y lo constituye - es lo propio del quehacer psicopatológico. (Esquema)

Lo singular y lo subjetivo. De la biología a la biografía.

No es solo un organismo, en tanto cuerpo anatómico, lo que constituye la vida, sino la historia, la biografía de esa vida y de cada uno, no reducida a lo biológico. Es de esa biografía de lo que va a dar cuenta lo psíquico y de lo que nos ocuparemos en psicopatología, inscribiéndose como un saber propio de lo humano.

En relación a que lo humano no se agota en lo orgánico, en lo biológico, se refiere Heidegger (26) cuando afirma: "que la fisiología y la química fisiológica, puedan investigar al ser humano en su calidad de organismo, desde la perspectiva de las ciencias naturales, no prueba en modo alguno que en eso "orgánico", es de- 
ORIGINALES Y REVISIONES

cir, el cuerpo científicamente explicado, resida la esencia del hombre. Esa opinión tiene tan poco valor como la que sostiene que la esencia de la naturaleza está encerrada en la energía atómica” (p. 28).

Como destaca Foucault, "el estudio de la patología mental exige métodos de análisis diferentes de los de la patología orgánica y solo por un artilugio del lenguaje podemos prestarles la misma significación a las enfermedades del cuerpo y a las enfermedades del espíritu... Una patología unitaria que utiliza los mismo métodos y los mismos conceptos en el dominio psicológico y en el fisiológico entra actualmente en la categoría del mito..." (32).

Continúa Foucault su reflexión al respecto señalando que lo que da cuenta del conocimiento del hombre en tanto sus componentes constitutivos, es decir, su ser biológico, su ser lingüístico y su ser económico social, ninguno de ellos agota, ni puede definir por si solo o en conjunto todo lo humano. Los tres componentes son ciencias que por si mismas tienen una entidad y saber específicos, pero ni la biología, ni la lingüística, ni las relaciones económico sociales en que se articula lo humano, da cuenta de la totalidad específica de lo que es el hombre..."no es lo biológico, lo lingüístico o lo económico lo que da cuenta del saber del hombre, sino sus representaciones..." (33).

El saber acerca del sujeto y de lo humano queda abierto a un saber particular y propio que en psicopatología constituiría su específico campo de conocimiento, su singularidad.

Dada esta singularidad de su subjetividad, por lo personalizado, específico e intransferible de la realidad de cada ser, no puede haber un patrón, una medida, una escala, unos ítems o cuestionarios que definan un ser abstracto ya dado, modelo único y homogéneo, como un referente común, en tanto que por su propia esencia, se es diverso y particular, con tantos esquemas y patrones diferentes como diversos seres existen. Cada ser tiene en su individuación un mundo propio y una historia y experiencia particular.

Zubiri señala al respecto: "una cosa es ser siempre el mismo, y otra cosa es ser siempre lo mismo. Una cosa es la individualidad como modulación concreta y concreción a lo largo del tiempo; otra cosa es la individualidad como constitución primaria... El unum la realidad sustantiva es siempre el mismo, la individuidad. Otra cosa es lo otro enormemente rico de la individualidad" (34).

Singularidad que F. Mora, señala a nivel de la morfología y fisiología del propio cerebro de cada uno: "el cerebro de cada ser humano (incluido los clones; gemelos univitelinos ...), es diferente en su morfología, tanto externa como interna, lo que conforma las bases de la singularidad e individualidad... el cerebro cambia constantemente en su física y en su química, en su anatomía y en su fisiología y todos estos cambios se expresan en los procesos mentales y en la conducta" (35).

La tendencia actual de abordar ciertas enfermedades orgánicas es de forma personalizada y especifica. Lo que es propio de la Inmunología, en otros campos, 
como la Oncología y otras especialidades, se están dando cada vez mas importancia e investigando, a los tratamientos personalizados para abordar, por ejemplo, el cáncer u otras enfermedades.

Lo equivalente en lo psíquico a lo personalizado en la inmunología, genética, etc., es lo subjetivo; un sujeto no aislado, ni en el vacío, sino un sujeto "encarnado", sujeto histórico y social, sujeto del inconsciente. A esto nos remite lo específico en la psicopatología.

El intentar reducir la práctica "psi", a la aplicación de escalas, cuestionarios, guías, etc., excluyendo o sustituyendo la historia clínica, el relato, etc., es limitarse o negarse a un conocimiento y un saber sobre la realidad particular y subjetiva de cada paciente portador de una historia propia, de una vida, una biografía, un sentir y un ser, que en cada uno es distinto, multiforme e intransferible. (Esquema)

Con tales prácticas, al uniformizarlo, homogenizarlo y perder su especificidad como sujeto, se le reduce a objeto, a una realidad estable, fija e inmutable, queriendo hacerla mensurable y objetiva por la bioestadística y el equilibrio numérico, contradiciendo la propia realidad de cada sujeto, en tanto devenir, en tanto que acontece.

En el decir de $\mathrm{M}^{\mathrm{a}}$ Zambrano, “...la persona es por una parte imprevisible en sus acciones y modos de conducta; nunca se conoce enteramente a una persona, aunque esta persona sea la propia; no se puede prever con certeza qué decisión tomará en un futuro ni siquiera dadas de antemano las circunstancias... una luz nueva pueda llegarle en cualquier instante; un horizonte mas amplio se le puede descubrir, un mayor conocimiento o una capacidad de entrega desconocida, o una energía sin precedentes..." (36).

De esta supresión del sujeto y de la intersubjetividad sustituyéndola por la homologación y estandarización de las conductas nos alerta H. Arendt señalando: ..."la conducta uniforme que se presta a la determinación estadística, por tanto a la predicción científicamente correcta, no es en modo alguno un ideal científico inofensivo. Las ciencias del comportamiento - anulando la subjetividad-apuntan a reducir al hombre en todas sus actividades a un animal de conducta condicionada..." (37).

El paradigma que parece ser emulado y que encarnaría el sueño de cierta psicopatología parece ser, por un lado, la homologación con la ingeniería en su tecnificación y robotización, buscando establecer relaciones objetivas en tanto cosificadas y mecánicas. De otro, con la cirugía, donde el órgano la víscera, la entraña, es mero objeto, cosa dañada a eliminar, cortar o restituir, y si fuese el caso transplantar, que como piezas de una máquina se pudiesen ensamblar a la manera de un mecano.

¿Es éste el paradigma de la psicopatología para algunos? Así lo parece cuando se intenta emular la labor propia del cirujano, que en su reduccionismo organicista, (tapando el resto del cuerpo, deja exclusivamente lo concreto del órgano a 
ORIGINALES Y REVISIONES

extirpar), petrifica, cosifica, y reduce a un órgano o víscera lesionado o anómalo, la tarea de su actuación. Vísceras u órganos que podrán verse por las pruebas y aparatos (endoscopia, escáner, biopsia, etc.). Pruebas que en lo psíquico se intenta equiparar, como parodia, con las escalas, cuestionarios, guías, test, etc., es decir, reducir lo psíquico a una parcela y no a la totalidad del ser, para intentar mensurarlo, como si pudiese existir una normalidad estadística impersonal y normativizadora.

¿Es que se puede desposeer al paciente psíquico para su estudio y conocimiento de su biografía, de su relato, de su historia, de su realidad, de su dolor y de su sufrimiento? (Lo que para la tragedia griega va a suponer el dolor y el sufrimiento que van a generar y desvelar la sabiduría, la conciencia de si y la relación a la verdad, como nos refiere Lasso de la Vega en su Introducción a las Tragedias de Sofocles ) (38).

Hay una verdad del hombre que está en su interior que no es la verdad de las ciencias en su formulación moderna, ni la verdad teológica o trascendental; y que nace de un ejercicio de indagación biográfica. Es lo que Canguilhem llama el Sentido Íntimo. Paralelamente a la filosofía y a la ciencia, el relato, la memoria, la autobiografía, dan cuenta del nacimiento de un nuevo sujeto.

¿Es que para un paciente su órgano, su víscera, es decir, sus entrañas no le son síntientes y vivenciados? ¿No alude a ello la metáfora "entrañable” - a las entrañas- no como mera víscera sino como lo profundo, lo íntimo, lo que da cuenta de ese ser que siente?, ¿y no es a este ser a quien vamos a tratar-en el doble sentido de trato y de tratamiento-? ¿No es esto lo que nos da entidad clínica propia de nuestro quehacer específico psicopatológico?

De la escucha en psicopatología.

Ahora bien, la cuestión está en que todo lo dicho no tiene mucho sentido, como no se haga una escucha del paciente. Pero hablar sobre la técnica de la escucha, es decir, como realizar la historia clínica, es otro capítulo, cuando menos tan importante o mas que lo aquí descrito.

El problema es: ¿Qué hay que escuchar?, ¿Qué escucha se hace? De poco servirá la anamnesis y la historia clínica- aunque el hecho de poder dejar hablar ya sería importante para el paciente al menos como catarsis - si no hay un saber hacer, en este caso, escuchar. Del saber escuchar se trata por parte del terapeuta, lo que puede y sabe escuchar del paciente. Qué dice en lo que dice y más allá de lo que dice (no ser un mero amanuense, recopilador de notas).

Ese saber escuchar lo identifica como terapeuta de lo "psi" a diferencia de otras escuchas (sociólogo, trabajador social, médico de cabecera, amigo, familia 
etc.) y a su vez de otras técnicas y teorías dentro de nuestro campo (psicoterapia sistémica, psicoanálisis, otras psicoterapias, cognitivismo, etc).

Quede claro al menos que se pueda dejar hablar, narrar la historia, porque la tendencia y deriva actual del "que no me cuenten historias" o el comenzar una exploración pasando cuestionarios, escalas, pruebas, etc., no suponga eliminar o sustituir la narración, la anamnesis, el relato, la demanda... en definitiva, el saber acerca del ser del paciente, el construir una historia clínica.

No confundamos los lugares y los quehaceres. Con ello habremos ganado en rigor científico, en profesionalidad y en humanidad.

Figura 1.

\section{$\left[\begin{array}{c}\text { SABER PSICOPATOLÓGICO } \\ \text { NO ANTAGONCOS, SNO CONPLEMENARRIOS }\end{array}\right]$}

SABER CLÍNICO

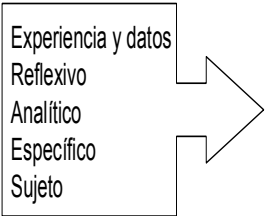

Fenom. emergentes $\longrightarrow$

Historia clínica

Anamnesis

Biografía-Patografía

Escucha y

Mirada clínica

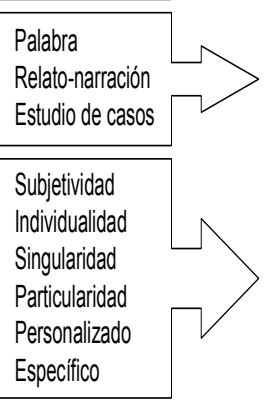

\section{SABER CIENTÍFICO}
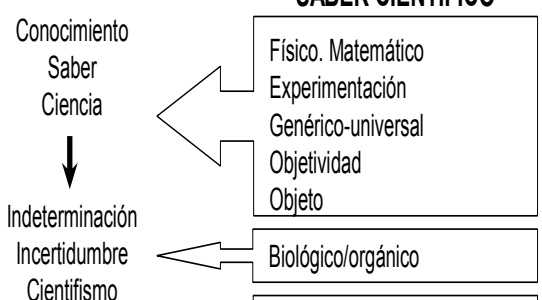

$\longrightarrow$ Biológico/orgánico

Cientifismo

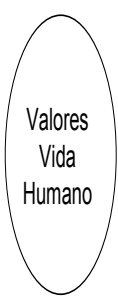

Pruebas funcionales Laboratorio Bioquímica-Neurotransmisores Radiografías-Escáner Biopsia-Anatomía patológica Genética

Pretensión cientifica:

- Escalas, Cuestionarios y

Guías clínicas

Objetividad

Mensurabilidad-Bioestadística

Modelos generales-Universales

Uniforme

Determinista

Genérico 
ORIGINALES Y REVISIONES

\section{BIBLIOGRAFÍA:}

(1) Lain Entralgo, P. La historia clínica. $3^{\text {a }}$ ed. Madrid: Triacastela. 1998

(2) García Gual, C. Introducción. En: Tratados Hipocráticos I. Madrid: Gredos, 1993; p.15

(3) Angosto, T. Freud y la patografía de los casos de histeria. Ponencia presentada al V Congreso de la European Asociación for the History of Psychiatry. Madrid; Sep 2002

(4) Ortega y Gasset, J. La rebelión de las masas, Madrid. Círculo de lectores; 1967; p. 104

(5) Szczeklik, A. Catarsis, Barcelona: Acantilado 2010; p 76

(6) Canguilhem, G. Escritos sobre la medicina. Buenos Aires: Amorrortu. 2004; p 36

(7) Montiel, L. Psicopatología y fenomenología de la corporeidad. En: Sociedad de Historia y Filosofía de la Psiquiatría, Fuentenebro, F. Rojo, A. cds, Madrid, 2005; p 64

(8) Peteiro, J. El autoritarismo científico. Madrid: Miguel Gómez 2010; p. 58-59

(9) Innerarity, D Claves de la Razón Practica n ${ }^{\circ} 209.2011$; p. 12

(10) Cassirer, E. Antropología filosófica. Madrid: FCE. 2009; p. 45

(11) Wagner, El País. (9-2-2008)

(12) López Ibor, J.J. recogida en: La H ${ }^{\mathrm{a}}$ Clínica. Lain Entralgo, P. Madrid: Triacastela 1998; p. 666

(13) Berrios, G. Sobre la medicina basado en la evidencia; . http//www. Psicoevidencias.es/novedades/editorial/on-evidence-bases-medicine.html

(14) Luria, A.R. Conciencia y lenguaje. Madrid: Pablo del Río. 1979; p. 22

(15) Althusser, L. Freud et Lacan. En: Positions. Paris: Eds. Sociales. 1976; p.28

(16) Damasio, A. El error de Descartes. Barcelona: Crítica. 2001; p. 154

(17) Rose, S. Tu cerebro mañana. Barcelona: Paidos. 2008; p. 280-281

(18) Etxenique, P.M. El Mundo-Campus (9-12-2009)

(19) Pascual-Leone, A. El País (29-X-2008)

(20) Sur, M. , Angelucci A, Sharma, S. Rewising Cortex; The role of patterned activity in development and plansticity of neocortical circuit. Journal of neurobiology, 1999, 41, n ${ }^{\circ} 1 ; 33-43$

(21) Noë, A. Fuera de la cabeza, Barcelona: Kairos, 2010: p. 78

(22) Lehrer, J. Proust y la neurociencia. Barcelona: Paidos. 2010; p.70

(23) Venter, C. El País (25-6-2000)

(24) Lain Entralgo, P. El silencio y la palabra del médico. Jano, 1980, nº 444; 20

(25) Lledó, E. Elogio de la infelicidad. Valladolid: Cuatro, 2005; p. 44-45

(26) Heidegger. M. Carta sobre el humanismo, $5^{\circ}$ reimpresión. Madrid: Alianza editorial. 2009; p. 11

(27) Etkin, A. Polan H.J, Kandel, E. Toward a neurobiology of psychotherapy: basic sciencie and clinical applications. Journal of Neuropsychiatric and clinical neurosciencies 17, 2005; 145-148

(28) Feyerabend, P. Diálogos sobre el conocimiento. Madrid: Cátedra, 1991; p.53

(29) Lain Entralgo, P. La curación por la palabra en la antigüedad clásica. Barcelona: Anthropos, 1987; p. 106

(30) Castilla del Pino, C. Historia crítica de la psiquiatría en el siglo XX. Rev Asoc. Esp. Neuropsiq. 2007, XXVII, 99; 114-115

(31) Akerlof, G. Animal Spirits. Barcelona: Gestión 2000. 2009; p. 93

(32) Foucault, M. Enfermedad mental y personalidad. Barcelona. Paidos 1984; p.20

(33) Foucault, M. Las palabras y las cosas, 10ª ed. Madrid: Siglo XXI. 1978; p 342

(34) Zubiri, X. Sobre la realidad. Barcelona: Planeta. 2011; p. 118 
(35) Mora, F. El cerebro humano: desafios para el siglo XXI. Eidon n ${ }^{\circ} 33$ mayo-junio 2010; p. 48-51

(36) Zambrano, $\mathrm{M}^{\mathrm{a}}$. Persona y democracia, $2^{\mathrm{a}}$ edic. Madrid: Siruela 2004; p. 158

(37) Arendt, H. La condición humana. Barcelona: Paidos 1998; P. 51-55

(38) Lasso de la Vega, J. Introducción. En: Sófocles. Tragedias. Madrid: Gredos, 1981; p.49 